\title{
Comparison of self-stigma and quality of life in patients with depressive disorders and schizophrenia spectrum disorders - a cross-sectional study
}

\author{
This article was published in the following Dove Press journal: \\ Neuropsychiatric Disease and Treatment \\ 24 November 2016 \\ Number of times this article has been viewed
}

\author{
Michaela Holubova ${ }^{1,2}$ \\ Jan Prasko' \\ Stanislav Matousek' \\ Klara Latalova' \\ Marketa Marackova' \\ Kristyna Vrbova' \\ Aleš Grambal' \\ Milos Slepecky ${ }^{3}$ \\ Marta Zatkova ${ }^{3}$ \\ 'Department of Psychiatry, Faculty \\ of Medicine and Dentistry, Palacky \\ University Olomouc, University \\ Hospital Olomouc, Olomouc, \\ ${ }^{2}$ Department of Psychiatry, Hospital \\ Liberec, Liberec, Czech Republic; \\ ${ }^{3}$ Department of Psychology \\ Sciences, Faculty of Social Science \\ and Health Care, Constantine the \\ Philosopher University in Nitra, \\ Nitra, Slovak Republic
}

Background: The views of one's self-stigma and quality of life (QoL) in patients with schizophrenia and depressive disorders are significant subjective notions, both being proven to affect patient's functioning in life. The objective of this study was to investigate the QoL and self-stigma in connection with demographic factors and compare the two groups of patients in terms of those variables.

Methods: In a cross-sectional study, the outpatients with schizophrenia spectrum disorders and depressive disorders completed the Quality of Life Satisfaction and Enjoyment Questionnaire, the Internalized Stigma of Mental Illness Scale, and a demographic questionnaire during a routine psychiatric control. Furthermore, both patients and their psychiatrists evaluated the severity of the disorder by Clinical Global Impression-Severity scale.

Results: The QoL of patients with depressive disorders or schizophrenia spectrum disorders did not significantly differ between the two groups. In both groups, unemployment was perceived to be a significant factor decreasing the QoL. Self-stigma was detected to be higher in patients with schizophrenia spectrum disorders than in patients with depressive disorders. A strong correlation was found between the two scales, meaning that those with higher levels of selfstigmatization were less prone to see their life as fulfilling and joyful.

Conclusion: This study shows that the degree of the internalized stigma can be an important aspect linked to the QoL irrespective of the diagnostic category.

Keywords: self-stigma, quality of life, depressive disorders, schizophrenia spectrum disorders

\section{Introduction}

Schizophrenia spectrum and depressive disorders are among the most common severe psychiatric diseases. Although both can vary in their course and outcome, many cases manifest as serious and handicapping long-term psychiatric conditions. As such, they often cause considerable psychological distress and disturb patients' psychological well-being and overall quality of life (QoL). ${ }^{1}$ Both disorders can profoundly affect the patient's ability to work (mainly due to long-term cognitive dysfunction and symptoms of the diseases), to function competently in marriage, partnership, and parental roles and to fulfill life needs in general. Both can be life threatening when they lead to suicidal tendencies; both present a major social and economic burden and entail a substantial treatment cost. ${ }^{2-5}$
Department of Psychiatry, Faculty of Medicine and Dentistry, Palacky University Olomouc, University Hospital Olomouc, IP Pavlova 6, 77520 Olomouc, Czech Republic Email praskojan@seznam.cz 
The QoL is a multidimensional concept intended to reflect the overall functioning and well-being of the patient in life. However, its definition is not uniform. The QoL concept is based mainly on the self-assessment of the patients about how they feel, what has happened to them, and how they enjoy their life activities. Several research studies aimed at determining the QoL in depressed and/or schizophrenic patients indicate a reduced QoL compared to that in healthy control groups. ${ }^{6-10}$

Both physical health and mental health have an impact on the QoL in patients with schizophrenia and depressive disorders. ${ }^{11}$ Both in psychiatry and in other fields of medicine, the QoL does not necessarily reflect the severity of disease although it typically correlates with it. ${ }^{9,12,13}$

One of the goals of this study was to find out whether patients with depression and schizophrenia differ significantly in their overall QoL. Significant differences in the QoL were previously found in patients with bipolar affective disorder and schizophrenia. ${ }^{12}$ Patients with bipolar affective disorder have a higher QoL.

Another aim of this study was to elucidate the extent of the self-stigmatization in the two patient groups. The awareness of psychiatric disorder by others can lead to labeling prejudices, attitudes, and dismissive behaviors of patients' relatives and people in their community, sometimes including health care professionals. Individuals with higher sensitivity to rejection and to other socially harmful stimuli are prone to the development of self-stigma. ${ }^{14,15}$ Stigmatized individuals can adopt perceived prejudgments of society against psychiatric patients and develop negative feelings about themselves, ie, self-stigmatize themselves. Self-stigmatization is a maladaptive psychosocial phenomenon distressing a significant number of psychiatric patients. ${ }^{16}$

Self-stigma is expressed by reduced self-esteem and amplified depression. Patients with a high level of self-stigma accept the social prejudices about people with the psychiatric disorder and thus are convinced of their inferiority, or untreatability of their mental problems. ${ }^{17}$

Patients feel embarrassment and shame about having a mental disorder. These emotional states limit social communications and weaken job-related functioning. When a person labels himself/herself as an individual who needs psychiatric treatment, this can lead to an additional decrease in self-esteem, which creates the self-stigma of looking for help. ${ }^{18}$ Some personality factors such as hopeful thinking and self-acceptance serve as factors promoting resilience against self-stigma in patients with anxiety disorder, other neurotic spectrum disorders, and depressive disorder. ${ }^{19}$ Existing research shows that sex, heredity, and education are not statistically significantly related to the degree of self-stigma, and the protective role of the partnership is equivocal. ${ }^{20-23}$ On the other hand, having stable employment was found to reduce the level of self-stigma. ${ }^{10,22}$

Stigma has emerged as a significant obstacle in the treatment of schizophrenia, depression, and other mental illnesses. Self-stigma can be linked to the suicidal behavior, ${ }^{5,14,24}$ stress, unemployment, social isolation, hopelessness ${ }^{4}$ and reduced adherence and the treatment effectiveness in psychiatric disorders. ${ }^{20,23,25-28}$ Kamaradova et al ${ }^{29}$ examined data from 332 patients with six psychiatric diagnoses (schizophrenia, bipolar disorders, depressive disorders, anxiety disorders, substance abuse disorders, and personality disorders). Selfstigma positively correlated with the severity of disorders, the doses of antidepressants, and the number of hospitalizations and psychiatrist visits, while negatively correlated with the adherence to treatment in all diagnostic groups. The level of self-stigma did not differ between diagnostic categories. It seems that the extent of the self-stigmatization does not depend on the specific diagnosis but rather on the severity of the disorder, assessed both subjectively and objectively. ${ }^{10,19,29}$

Some studies point to a significant relationship between the QoL and self-stigma, showing that self-stigmatization leads to a lower QoL in patients with schizophrenia and also with depression. ${ }^{13,30}$ This study offers yet another slightly different comparison between the two aspects of well-being and their relationship in both groups.

\section{Aim of the study and the main hypotheses}

The objective of this study was to compare the self-stigma and QoL connected with demographic factors in the group of patients with schizophrenia spectrum disorders and depressive disorders. The research hypotheses were based on our previous exploration of the topic: ${ }^{10,13,29,31}$

(1) The QoL in patients with schizophrenia spectrum disorders is lower than in patients with depression.

(2) The level of self-stigma is higher in patients with schizophrenia spectrum disorders than in depressed patients.

(3) The QoL is lower in unemployed patients than in employed patients.

(4) The patients with higher levels of self-stigma have a lower QoL in both diagnostic groups.

\section{Methods}

The study design was as follows: 140 psychiatrists in the Czech Republic were contacted, of whom 20 agreed to participate in the study, collaborating in collecting the 
patient data. These specialists distributed patient questionnaires, filled in by the patients during the routine psychiatric examination.

\section{Participants}

The study group consisted of psychiatrically disordered patients with schizophrenia spectrum disorders and depressive disorders, who had been diagnosed according to the International Classification of Diseases, Tenth Revision (ICD-10). ${ }^{32}$ The study was conducted between March 2014 and November 2015. The inclusion criteria were age from 18 to 60 years, both sexes, and diagnosis of schizophrenia spectrum disorders (schizophrenia, schizoaffective disorder, persistent delusional disorder, and acute polymorphic psychotic disorder) or depressive disorders according to ICD-10 diagnostic criteria. ${ }^{32}$ The exclusion criteria were severe acute symptomatology and comorbidity with substance abuse, organic brain disease, and severe somatic disease, $<18$ years of age, current hospitalization, and intellectual disability. Acute symptomatology was excluded by evaluation by psychiatrists, who had known the patients long term. Patients attending an outpatient psychiatric facility were in stable condition, implying, according to the psychiatrist, that they did not have acute symptomatology, did not require hospitalization, did not need changes in medication or other therapeutic intervention, and their medication was the same in the last three months. Only patients who filled in all questionnaires were included in the study.

\section{Assessment instruments}

Several questionnaires were filled in by the participants.

\section{The Quality of Life Satisfaction and Enjoyment Questionnaire (Q-LES-Q)}

The Q-LES-Q, having 93 items, is divided into eight domains to assess. ${ }^{33}$ The patients assess each domain by choosing one number from a 5-point Likert scale according to their level of satisfaction with the item. The completion takes 20-30 minutes. Patients fulfill the domains of Physical health, Feelings, Leisure, Household, Work, School/study, Social relations, and General and a sum of the QoL. Müllerova fully validated the Czech version of the Q-LES-Q. ${ }^{34}$

\section{The Internalized Stigma of Mental Illness Scale (ISMI)}

The questionnaire has 29 items that evaluate five areas of the internalized stigma. ${ }^{35,36} \mathrm{~A}$ higher score points to a greater level of self-stigma. The scale assesses five facets of selfstigma - Alienation, Perceived discrimination, Stereotype endorsement, Social withdrawal, and Stigma resistance. ${ }^{35}$
Internal consistency of the scale is excellent. ${ }^{35}$ Cronbach's $\alpha$ of the Czech translation is high $(\alpha=0.91)$, and the excellent reliability of the scale is also shown by the split-half method (Spearman-Brown coefficient $=0.93$ ) and test-retest 3 weeks after the first measurement $(r=0.90, P<0.001) .{ }^{15}$

\section{Clinical Global Impression (CGI)}

The scale represents a global assessment of severity of psychopathology. ${ }^{37}$ The CGI-severity score is based on symptoms, behaviors, and functioning over the last 7 days, both reported and observed. It is evaluated on the 7-point scale extending from 1 (normal) to 7 (most extremely ill). The evaluation is performed by the professional rater (psychologist or psychiatrist) using the objective CGI (objCGI). The patient also assesses himself/herself by the subjective CGI (subjCGI), which includes seven levels of severity of the psychopathology. ${ }^{37}$ Internal consistency of the scale is satisfactory. ${ }^{38}$

\section{Demographic questionnaire}

The questionnaire covers information about sex, age, employment status, education, marital status, heredity, type of disability pension, the number of siblings, the age of the disease onset, the duration of the disorder, and the number of psychiatric hospitalizations and current medication.

\section{Statistical evaluation and ethics}

The statistical packages Prism 3 and SPSS 24.0 were used as the software for the statistical analysis of the data. Demographic facts and total scores mean of the scales were calculated using descriptive statistics. The mean, median, standard deviation, and distribution of data have been computed. The Shapiro-Wilk $W$ test determined the Gaussian distribution of the data. The unpaired $t$-test and the Mann-Whitney $U$-tests were used for the comparisons of the mean. Relationships between variables were analyzed by Pearson or Spearman correlation coefficient, partial correlation with controlling for age, and backward stepwise multiple regression. The Fisher test or chi-square test verified the connection between alternative variables (sex, education, marital status, and partnership). Since individual elements determined by correlation statistics may interfere with one another, multiple regression analysis was used to identify the most important factors. The $5 \%$ level of significance was considered satisfactory for all statistical tests. The local ethics committee in Olomouc University Hospital approved the study. The study was conducted in agreement with the latest version of the Declaration of Helsinki and the standards of Good Clinical Practice. ${ }^{39}$ All the patients signed the written informed consent. 


\section{Results}

\section{Sample characteristics}

The questionnaires were filled in by a total of 183 outpatients diagnosed with depression or schizophrenia spectrum disorders at various participating psychiatric outpatient centers. The sample comprised 121 females $(66 \%)$.
The patients with schizophrenia spectrum disorders were significantly younger, their disease started significantly earlier and lasted longer, and they experienced significantly more hospitalizations and were more often unmarried or without a partner (Table 1). The most frequent diagnosis among schizophrenia spectrum disorders was schizophrenia (67\%),

Table I Demographic and clinical characteristics of the patients with schizophrenia spectrum disorders and depressive disorders

\begin{tabular}{|c|c|c|c|c|}
\hline Variable & $\begin{array}{l}\text { All patients } \\
(n=183)\end{array}$ & $\begin{array}{l}\text { Schizoprenia spectrum } \\
\text { disorders }(n=103)\end{array}$ & $\begin{array}{l}\text { Depression } \\
(\mathrm{n}=\mathbf{8 0})\end{array}$ & $\begin{array}{l}\text { Statistical comparison of schizophrenia } \\
\text { spectrum disorders and depression }\end{array}$ \\
\hline Age (years) & $46.4 \pm 12.8$ & $42.0 \pm 10.2$ & $52.2 \pm 13.6$ & Unpaired $t$-test: $t=5.77, d f=|80 ; P<0.000|$ \\
\hline Gender (M:F) & $62: 121$ & $41: 62$ & $21: 59$ & Fisher's exact test; ns \\
\hline Age of disease onset (years) & $33.1 \pm 13.5$ & $26.1 \pm 9.0$ & $42.4 \pm 12.9$ & Unpaired $t$-test: $t=9.89, d f=|74 ; P<0.000|$ \\
\hline Duration of the disorder (years) & $13.3 \pm 10.0$ & $15.4 \pm 9.5$ & $10.5 \pm 10.1$ & Mann-Whitney test: $U=2,469 ; P<0.000 \mathrm{I}$ \\
\hline Number of hospitalizations & $2.5 \pm 3.5$ & 4. $1 \pm 4.0$ & $0.5 \pm 1.1$ & Mann-Whitney test: $U=756 ; P<0.000 \mathrm{I}$ \\
\hline \multicolumn{5}{|l|}{ Psychiatric heredity } \\
\hline Other disorder & $53(29)$ & $39(38)$ & $14(18)$ & Chi-square, $d f=10.4,3 ; P<0.05$ \\
\hline Same disorder & $29(16)$ & $15(15)$ & $14(18)$ & \\
\hline Without & $94(5 I)$ & $47(46)$ & 47 (59) & \\
\hline Not completed & $7(4)$ & $2(2)$ & $5(6)$ & \\
\hline \multicolumn{5}{|l|}{ Education } \\
\hline Elementary & $14(8)$ & $9(9)$ & 5 & Chi-square, $d f=I .2,3$; ns \\
\hline Vocational training & $44(24)$ & $25(24)$ & 19 & \\
\hline Secondary school & $91(50)$ & $52(5 I)$ & 39 & \\
\hline University & $33(18)$ & $16(16)$ & 17 & \\
\hline Not completed & I & I & - & \\
\hline \multicolumn{5}{|l|}{ Marital status } \\
\hline Single & 7I (38.8) & $6 I(59.0)$ & II (I3.8) & Chi-square, $d f=39.2,4 ; P<0.0001$ \\
\hline Married & $68(37.2)$ & $24(23.1)$ & $44(56.0)$ & \\
\hline Divorced & $35(19.1)$ & $15(14.3)$ & $20(25.0)$ & \\
\hline Widowed & $3(1.6)$ & I (0.9) & $2(2.5)$ & \\
\hline Not completed & $6(3.3)$ & $3(2.7)$ & $3(3.8)$ & \\
\hline \multicolumn{5}{|l|}{ Partner } \\
\hline No & 89 (49) & $66(64)$ & $23(29)$ & Chi-square, $d f=22.8,2 ; P<0.000 \mathrm{I}$ \\
\hline Yes & $88(48)$ & $34(33)$ & $54(68)$ & \\
\hline Not completed & $6(3)$ & $3(3)$ & $3(4)$ & \\
\hline \multicolumn{5}{|l|}{ Employment } \\
\hline Yes & $67(37)$ & $33(32)$ & $34(42.5)$ & Chi-square, $d f=3.5, I ;$ ns $(P=0.0599)$ \\
\hline No & $110(60)$ & $70(68)$ & $40(50)$ & \\
\hline Not completed & $6(3)$ & - & $6(7.5)$ & \\
\hline objCGI severity & $3.7 \pm 1.2$ & 4. $1 \pm 1.0$ & $3.1 \pm 1.2$ & Mann-Whitney test: $U=2,296 ; P<0.000$ I \\
\hline subCGI severity & $2.6 \pm 1.3$ & $2.8 \pm 1.4$ & $2.5 \pm 1.0$ & Mann-Whitney test: $U=3,476$; ns \\
\hline objCGI-subCGI severity & $\mathrm{I} . \mathrm{I} \pm \mathrm{I} .3$ & $1.4 \pm 1.4$ & $0.7 \pm 1.0$ & Mann-Whitney test: $U=2,572 ; P<0.0005$ \\
\hline \multicolumn{5}{|l|}{ ISMI } \\
\hline Alienation & $12.7 \pm 3.9$ & $13.3 \pm 3.9$ & $11.9 \pm 3.7$ & Unpaired $t$-test: $t=2.5, d f=\mid 79 ; P<0.05$ \\
\hline Stereotype endorsement & $13.1 \pm 3.3$ & $14.0 \pm 3.4$ & $12.0 \pm 2.7$ & Unpaired $t$-test: $t=4.3, d f=|79 ; P<0.000|$ \\
\hline Perceived discrimination & $10.1 \pm 3.3$ & $1 \mathrm{I} .1 \pm 3.3$ & $8.7 \pm 2.7$ & Mann-Whitney test: $U=2,370 ; P<0.000$ I \\
\hline Social withdrawal & $12.4 \pm 3.9$ & $13.0 \pm 3.8$ & $11.6 \pm 3.8$ & Unpaired $t$-test: $t=2.6, d f=179 ; P<0.05$ \\
\hline Stigma resistance & $12.5 \pm 2.3$ & $12.6 \pm 2.4$ & $12.5 \pm 2.3$ & Unpaired $t$-test: $t=0.4, \mathrm{df}=179 ; \mathrm{ns}$ \\
\hline ISMI overall score & $60.8 \pm 13.6$ & $64.0 \pm 13.7$ & $56.8 \pm 12.3$ & Unpaired $t$-test: $t=3.7, d f=179 ; P<0.0005$ \\
\hline \multicolumn{5}{|l|}{ Q-LES-Q } \\
\hline Physical health (maximum 65p) & $40.8 \pm 9.9$ & $41.8 \pm 9.8$ & $39.5 \pm 9.9$ & Unpaired $t$-test: $t=1.6, d f=|8|$; ns \\
\hline Feelings (maximum 70p) & $47.1 \pm 10.6$ & $46.3 \pm 10.6$ & $48.0 \pm 10.6$ & Unpaired $t$-test: $t=I .0, d f=\mid 8 I$; ns \\
\hline Work (maximum 65p) & $31.3 \pm 19.1$ & $27.8 \pm 18.1$ & $35.9 \pm 19.4$ & Mann-Whitney test: $U=3,16 \mathrm{I} ; P<0.0 \mathrm{I}$ \\
\hline Household (maximum 50p) & $35.8 \pm 9.5$ & $35.0 \pm 9.0$ & $36.8 \pm 10.0$ & Mann-Whitney test: $U=3,486 ; n s$ \\
\hline School/study (maximum 50p) & $13.2 \pm 8.5$ & $13.5 \pm 8.8$ & $12.8 \pm 8.1$ & Mann-Whitney test: $U=3,991$; ns \\
\hline Leisure (maximum 30p) & $20.4 \pm 5.5$ & $20.1 \pm 5.4$ & $20.8 \pm 5.5$ & Unpaired $t$-test: $t=0.8, d f=\mid 8 I$; ns \\
\hline Social activities (maximum 55p) & $36.0 \pm 9.2$ & $35.7 \pm 9.2$ & $36.5 \pm 9.1$ & Unpaired $t$-test: $t=0.6, d f=\mid 8 I$; ns \\
\hline General (max 80p) & $51.2 \pm 11.9$ & $51.5 \pm 12.1$ & $50.8 \pm 11.8$ & Unpaired $t$-test: $t=0.4, d f=\mid 8 I ; n s$ \\
\hline Sum of Q-LES-Q (maximum 465p) & $275.6 \pm 58.9$ & $271.5 \pm 58.0$ & $280.9 \pm 59.9$ & Unpaired $t$-test: $t=I . I, d f=\mid 8 I$; ns \\
\hline Sum of Q-LES-Q (\%) & $59.3 \pm 12.7$ & $58.4 \pm 12.5$ & $60.4 \pm 12.9$ & Unpaired $t$-test: $t=I . I, d f=\mid 8 I$; ns \\
\hline
\end{tabular}

Note: Data presented as $\mathrm{n}(\%)$ or mean \pm standard deviation.

Abbreviations: F, female; ISMI, Internalized Stigma of Mental Illness Scale; M, male; ns, nonsignificant; objCGI, objective Clinical Global Impression; p, points; Q-LES-Q, Quality of Life Satisfaction and Enjoyment Questionnaire; subjCGI, subjective Clinical Global Impression. 
particularly paranoid type (58\%), followed by schizoaffective disorder (29\%), acute polymorphic psychotic disorder $(2 \%)$, and persistent delusional disorder (2\%). Both patient groups felt themselves similarly severely mentally ill, yet the schizophrenia spectrum groups came out as more severely ill in the external, and consensually more objective, assessment made by a trained psychiatrist.

The overall QoL (sum of Q-LES-Q) and the QoL in all subscales except Work do not differ between the patient groups with schizophrenia spectrum disorders and depressive disorders; the overall QoL is similar regardless of the mental illness.

The patients with schizophrenia spectrum disorders stigmatized themselves significantly more than patients with depressive disorders (especially in overall ISMI score and subscales for Stereotype endorsement and Perceived discrimination). The differences in Alienation and Social withdrawal were somewhat less marked but still significant. Only the Stigma resistance subscale score did not differ in both groups (Table 1).

\section{Treatment}

One hundred and eighty-one patients $(98.9 \%)$ reported that they used prescribed antidepressive or antipsychotic medication. Most/a majority of the patients $(n=156)$ indicated that they used the medication in a prescribed dosage regularly $(85.2 \%), 12$ patients $(6.5 \%)$ reported taking the medication irregularly (sometimes, they had forgotten to use it). Two patients $(1.1 \%)$ stated that they had not used the medication at all. The precise type and dosage of the medication were not monitored in this study.

\section{Relationship between the QoL and measured demographic or clinical characteristics}

The age of the patient correlated only with the Physical health domain of the Q-LES-Q (Pearson's $r=-0.16 ; P<0.05$ ) but not with other domains or sum of Q-LES-Q. The sum of Q-LES-Q significantly negatively correlated with the disease severity assessed subjectively (subjCGI), and objectively (objCGI) after controlling for age (Table 2). The difference between objCGI and subjCGI positively correlated after controlling for age with the sum of Q-LES-Q as well. ObjCGI and subjCGI significantly correlated with all domains of Q-LES-Q except the domain School/study.

The average values of sum of Q-LES-Q did not statistically differ between sexes, marital or partnership status, or across different education groups (Table 3). However, employed patients described higher QoL than unemployed patients, the difference being statistically significant.

\section{Relationship between self-stigma and measured demographic or clinical characteristics}

Self-stigma, as measured by ISMI overall score, did not correlate with age (ISMI overall score Pearson's $r=-0.11$; nonsignificant). However, ISMI overall score significantly positively correlated with the number of hospitalizations, objCGI, and subjCGI and negatively with the difference between objCGI-subjCGI severity after controlling for age (Table 4).

Regarding the role of different demographic characteristics on self-stigma, there were no differences between sexes in the mean ISMI overall score. However, employed patients stigmatized themselves less than unemployed patients (Table 5). Similarly, the patients who had a partner stigmatized themselves less than patients without a partner. The effect of formal education was also significant, as the patients who achieved higher levels of education stigmatized themselves less. Marital status also had influence on the mean score of the ISMI overall rating (Table 5).

\section{Relationship between QoL and self- stigma}

The sum of the QoL significantly negatively correlated with all domains of self-stigma except for subscale School/study (Table 6).

\section{Regression analysis}

Stepwise regression analysis

Since various factors significantly related to the main outcome criteria, multiple regression analysis (backward elimination stepwise regression) was completed to identify the most important factors linked to the overall Q-LES-Q as the dependent variable. The regression has been weighted by the age of the patients. All entering factors were controlled for the collinearity. The independent variables entered into the regression analysis were Stigma resistance, partner, duration of the disorder, psychiatric heredity, education, sex, employment, objCGI-subCGI-severity, marital status, patient's diagnosis, number of hospitalizations, objCGI-severity, alienation, age of disease onset, and ISMI overall score. The resulting model explained $55.0 \%$ of the dependent variable $(P<0.001)$. The statistically significant factors connected to the sum of Q-LES-Q after eight steps of regression analysis were employment, the difference between objCGI-subjCGIseverity scale, subjCGI, and ISMI overall rating (Table 7). 
Table 2 Partial correlations between demographic or clinical variables and quality of life in the whole sample after controlling for age

\begin{tabular}{|c|c|c|c|c|c|c|}
\hline Domain & $\begin{array}{l}\text { Age of onset } \\
\text { of disorder }\end{array}$ & $\begin{array}{l}\text { Duration } \\
\text { of disorder }\end{array}$ & objCGI & subCGI & objCGI-subCGI & $\begin{array}{l}\text { Number of } \\
\text { hospitalizations }\end{array}$ \\
\hline Physical health & 0.14 & -0.15 & $-0.32 * * *$ & $-0.54^{* * *}$ & $0.25 * *$ & 0.06 \\
\hline Feelings & 0.12 & -0.13 & $-0.32 * * *$ & $-0.54 * * *$ & $0.25 * *$ & -0.06 \\
\hline Work & 0.06 & -0.40 & $-0.42 * * *$ & $-0.38^{* * *}$ & -0.02 & $-0.24^{* *}$ \\
\hline Household & 0.07 & -0.10 & $-0.36 * * *$ & $-0.48 * * *$ & 0.15 & -0.16 \\
\hline School/study & -0.10 & -0.01 & -0.09 & -0.08 & -0.01 & -0.05 \\
\hline Leisure & 0.09 & -0.11 & $-0.26 * *$ & $-0.37^{* * *}$ & 0.13 & -0.09 \\
\hline Social activities & 0.10 & -0.10 & $-0.28 * * *$ & $-0.37 * * *$ & 0.12 & -0.09 \\
\hline General & 0.13 & -0.13 & $-0.37 * * *$ & $-0.52 * * *$ & $0.17 *$ & -0.01 \\
\hline Sum of Q-LES-Q & 0.12 & -0.13 & $-0.48 * * *$ & $-0.60 * * *$ & $0.17 *$ & -0.11 \\
\hline
\end{tabular}

Notes: Statistically significant correlations (bold values), depending on the strength of correlation: $* P<0.05, * * P<0.01$, or $* * * P<0.001$.

Abbreviations: objCGI, objective Clinical Global Impression; Q-LES-Q, Quality of Life Satisfaction and Enjoyment Questionnaire; subjCGI, subjective Clinical Global Impression.

\section{Discussion}

The research sample of this outpatient study has the typical demographic characteristics of schizophrenia spectrum disorder and depressive disorder. The schizophrenia spectrum

Table 3 Average value of sum of Q-LES-Q ( \pm standard deviation of each group/individual values) as a function of various demographic characteristics

\begin{tabular}{|c|c|}
\hline \multicolumn{2}{|l|}{ Sex } \\
\hline Men $(n=62)$ & $263.9 \pm 58.1$ \\
\hline \multirow[t]{2}{*}{ Women $(n=|2|)$} & $281.6 \pm 58.6$ \\
\hline & $\begin{array}{l}\text { Unpaired } t \text {-test: } t=1.9, \\
d f=|8| \text {; ns }(P=0.053)\end{array}$ \\
\hline \multicolumn{2}{|l|}{ Employment } \\
\hline No $(n=108)$ & $257.3 \pm 51.5$ \\
\hline \multirow[t]{2}{*}{ Yes $(n=67)$} & $307.4 \pm 57.6$ \\
\hline & $\begin{array}{l}\text { Unpaired } t \text {-test: } t=6.1 \text {, } \\
d f=|8| ; P<0.000 \mid\end{array}$ \\
\hline \multicolumn{2}{|l|}{ Having a partner } \\
\hline No $(n=89)$ & $270.2 \pm 57.7$ \\
\hline \multirow[t]{2}{*}{ Yes $(n=94)$} & $280.8 \pm 59.8$ \\
\hline & $\begin{array}{l}\text { Unpaired } t \text {-test: } t=1.2 \text {, } \\
d f=|8| \text {; ns }\end{array}$ \\
\hline \multicolumn{2}{|l|}{ Education } \\
\hline Elementary $(n=14)$ & $257.1 \pm 53.8$ \\
\hline Vocational training $(n=44)$ & $273.3 \pm 52.7$ \\
\hline Secondary school $(\mathrm{n}=9 \mathrm{l})$ & $271.0 \pm 63.6$ \\
\hline \multirow[t]{4}{*}{ University $(n=34)$} & $298.7 \pm 50.5$ \\
\hline & One-way ANOVA: \\
\hline & $F=2.5, d f=182 ; n s$ \\
\hline & $(P=0.06)$ \\
\hline \multicolumn{2}{|l|}{ Marital status } \\
\hline Single $(n=7 I)$ & $268.7 \pm 58.5$ \\
\hline Married $(n=68)$ & $280.7 \pm 63.4$ \\
\hline Divorced $(n=35)$ & $276.9 \pm 52.6$ \\
\hline \multirow{3}{*}{ Widowed $(n=3)$} & $294.3 \pm 48.6$ \\
\hline & One-way ANOVA: \\
\hline & $F=0.7, d f=173 ; n s$ \\
\hline
\end{tabular}

Abbreviations: ANOVA, analysis of variance; ns, nonsignificant; Q-LES-Q, Quality of Life Satisfaction and Enjoyment Questionnaire. group was younger, had an earlier onset of the disorder and a higher number of hospitalizations, were more frequently single or without a partner, and were more frequently unemployed. These findings reflect the distribution, demographics, and essence of each disorder (schizophrenia is a psychotic disorder where the disease onset is at a younger age, when people just start to have a partner and find a job, while depression typically starts later, most commonly in middle age, when many individuals are married and have a job).

As for the study hypotheses, the first hypothesis was that "the quality of life is lower for the schizophrenia spectrum disorders patients as compared with the depressive patients." This hypothesis was not confirmed in the study. The QoL as assessed by the Q-LES-Q overall score of the two patient groups was nearly the same. When looking at the subscales, there was no statistical difference between subscales of Q-LES-Q except for the Work subscale, where the patients with depressive disorders rated this life area significantly higher than patients with schizophrenia spectrum disorders (Table 1). It seems that patients with schizophrenia spectrum disorders have particularly limited capacity to succeed in the job market and that they find this situation deeply distressful. The negative result for the QoL as a whole is surprising because our research group comparison of bipolar affective disorder and schizoprenia published several years ago showed higher Q-LES-Q in patients with bipolar disorder than in patients with schizophrenia spectrum disorders. ${ }^{12}$ The present result indicates that the QoL of the patients with depressive disorders is subjectively experienced as bad as the QoL of patients with schizophrenia spectrum disorders.

The second hypothesis was that "the level of self-stigma is higher in schizophrenia spectrum disorders patients in comparison to the patients with depression." This hypothesis was confirmed by this study. The result is contradictory to the 
Table 4 Partial correlations between self-stigma and its components measured by ISMI and demographic and clinical characteristics after controlling by the age

\begin{tabular}{|c|c|c|c|c|c|c|}
\hline $\begin{array}{l}\text { Demographic/clinical } \\
\text { characteristics }\end{array}$ & $\begin{array}{l}\text { Overall } \\
\text { score }\end{array}$ & Alienation & $\begin{array}{l}\text { Stereotype } \\
\text { endorsement }\end{array}$ & $\begin{array}{l}\text { Perceived } \\
\text { discrimination }\end{array}$ & $\begin{array}{l}\text { Social } \\
\text { withdrawal }\end{array}$ & $\begin{array}{l}\text { Stigma } \\
\text { resistance }\end{array}$ \\
\hline Onset of the disorder & -0.13 & -0.13 & $-0.17 *$ & $-0.23 * *$ & -0.11 & 0.06 \\
\hline Duration of the disorder & 0.16 & 0.16 & $0.20 *$ & $0.25 * *$ & 0.13 & -0.03 \\
\hline Number of hospitalizations & $0.20 *$ & $0.18^{*}$ & 0.14 & $0.34^{* * *}$ & $0.20 *$ & -0.09 \\
\hline objCGI-severity & $0.32 * * *$ & $0.26 * *$ & $0.25 * *$ & $0.28 * * *$ & $0.30 * * *$ & $0.20 *$ \\
\hline subCGI-severity & $0.50 * * *$ & $0.43 * * *$ & $0.42 * * *$ & $0.30 * * *$ & $0.48^{* * *}$ & $0.39 * * *$ \\
\hline objCGI-subCGI severity & $-0.2 I *$ & $-0.20 *$ & $-0.20^{*}$ & -0.04 & $-0.21 *$ & $-0.22 * *$ \\
\hline
\end{tabular}

Notes: Statistically significant correlation (bold values): $* P<0.05 ; * * P<0.0$ I; $* * * P<0.001$.

Abbreviations: ISMI, Internalized Stigma of Mental Illness Scale; objCGI, objective Clinical Global Impression; subjCGI, subjective Clinical Global Impression.

results of our previous study of Kamaradova et $\mathrm{al},{ }^{29}$ which showed no differences between diagnostic groups. Since the design of the study and the methodology of measurement were the same, the only difference between the two studies was in the design of data collection. In the case study of Kamaradova et al, ${ }^{29}$ the data were collected at the outpatient's psychiatric department of the University Hospital Olomouc, while the data of this study were obtained from a varied

Table 5 Levels of self-stigma as measured by ISMI overall score in various demographic groups

\begin{tabular}{|c|c|}
\hline & ISMI overall score \\
\hline \multicolumn{2}{|l|}{ Sex } \\
\hline Men $(n=62)$ & $63.2 \pm 13.7$ \\
\hline \multirow[t]{2}{*}{ Women $(n=119)$} & $59.6 \pm 13.4$ \\
\hline & Unpaired $t$-test: $t=1.7, d f=179 ; n s$ \\
\hline \multicolumn{2}{|l|}{ Employment } \\
\hline No $(n=108)$ & $64.2 \pm 13.3$ \\
\hline \multirow[t]{2}{*}{ Yes $(n=67)$} & $56.2 \pm 12.7$ \\
\hline & Unpaired $t$-test: $t=3.9, d f=|73 ; P<0.00|$ \\
\hline \multicolumn{2}{|l|}{ Having a partner } \\
\hline No $(n=87)$ & $63.6 \pm 14.6$ \\
\hline \multirow[t]{2}{*}{ Yes $(n=88)$} & $59.0 \pm 12.0$ \\
\hline & Unpaired $t$-test: $t=2.3, d f=173 ; P<0.05$ \\
\hline \multicolumn{2}{|l|}{ Education } \\
\hline Elementary $(n=\mid 4)$ & $62.8 \pm 14.5$ \\
\hline Vocational training $(n=43)$ & $61.1 \pm 13.9$ \\
\hline Secondary school $(n=90)$ & $62.6 \pm 13.4$ \\
\hline \multirow[t]{4}{*}{ University $(n=33)$} & $55.0 \pm 12.3$ \\
\hline & One-way ANOVA: $F=2.7, d f=179 ; P<0.05$ \\
\hline & Bonferroni's multiple comparison test: \\
\hline & secondary $>$ university \\
\hline \multicolumn{2}{|l|}{ Marital status } \\
\hline Single $(n=7 I)$ & $63.8 \pm \mid 4.5$ \\
\hline Married $(n=68)$ & $58.8 \pm I 1.6$ \\
\hline Divorced $(n=33)$ & $62.3 \pm 14.2$ \\
\hline Widowed $(n=3)$ & $48.0 \pm 7.9$ \\
\hline
\end{tabular}

One-way ANOVA: $F=2.7, d f=174 ; P<0.05$ Bonferroni's multiple comparison test: $\mathrm{ns}$

Note: Data presented as mean \pm standard deviation.

Abbreviations: ANOVA, analysis of variance; ISMI, Internalized Stigma of Mental Illness Scale; ns, nonsignificant. group of outpatient facilities. While it is possible that the discordant results are due to one method of data collection being unintentionally skewed, it is also possible that it is simply the effect of statistical uncertainty. Further inquiry is needed to elucidate the answer to this question.

The third hypothesis was that "the quality of life is lower for unemployed patients in comparison with the employed ones." This hypothesis was confirmed with a high level of confidence, higher than that found for other collected demographic factors. The finding shows the crucial role of employment, with the concurrent income it brings, the meaningful spending of time, and self-esteem for being beneficial to others. Here, it should be noted that the Czech Republic is a country with a high level of social security and solidarity, where seriously ill people are eligible for a state-run disability pension. Therefore, the subsistence aspect of the additional income might not be as important in our study as perhaps in other societies. The finding indicates that programs of assisted employment for both patients with depressive disorders and patients with schizophrenia spectrum disorders can be a sound and beneficial policy.

The fourth and principal hypothesis of this study was that "the patients with higher levels of self-stigma have a lower quality of life." This hypothesis was confirmed; this being in agreement with the results of previous studies. ${ }^{13,30}$ Patients who self-stigmatize themselves more due to their mental disorder tend to regard themselves as inferior, incompetent at fulfilling their needs and roles, limited in their skills and general life functioning and unable to succeed in life. This brings about reduced hope and self-acceptance, having an impact on the overall perspective of life and ultimately the perceived actual QoL. ${ }^{19}$

The self-stigma was found to correlate significantly with the number of hospitalizations. This seems to be in agreement with common sense - those who have experienced more hospitalizations are more likely to have met discrimination 
Table 6 Partial correlations between Q-LES-Q subscales and components of ISMI in the whole sample after controlling by the age

\begin{tabular}{|c|c|c|c|c|c|c|}
\hline $\begin{array}{l}\text { Domain of } \\
\text { Q-LES-Q }\end{array}$ & $\begin{array}{l}\text { Overall score } \\
\text { of ISMI }\end{array}$ & Alienation & $\begin{array}{l}\text { Stereotype } \\
\text { endorsement }\end{array}$ & $\begin{array}{l}\text { Perceived } \\
\text { discrimination }\end{array}$ & $\begin{array}{l}\text { Social } \\
\text { withdrawal }\end{array}$ & $\begin{array}{l}\text { Stigma } \\
\text { resistance }\end{array}$ \\
\hline Physical health & $-0.44 * * *$ & $-0.39 * * *$ & $-0.37 * * *$ & $-0.3 \mathbf{I} * * *$ & $-044 * * *$ & $-0.29 * * *$ \\
\hline Feelings & $-0.56 * * *$ & $-0.50 * * *$ & $-0.48 * * *$ & $-0.37 * * *$ & $-0.50 * * *$ & $-0.37 * * *$ \\
\hline Work & $-0.36 * * *$ & $-0.28 * * *$ & $-0.29 * * *$ & $-0.3 \mathbf{I} * * *$ & $-0.33 * * *$ & $-0.18^{*}$ \\
\hline Household & $-0.4 I * * *$ & $-0.34 * * *$ & $-0.35 * * *$ & $-0.28 * * *$ & $-0.35^{* * *}$ & $-0.30 * * *$ \\
\hline School/study & -0.11 & -0.11 & -0.06 & -0.09 & -0.08 & $-0.19^{*}$ \\
\hline Leisure & $-0.30 * * *$ & $-0.30 * * *$ & $-0.23 * *$ & $-0.20 *$ & $-0.29 * * *$ & $-0.20 *$ \\
\hline Social activities & $-0.44^{* * *}$ & $-0.37 * * *$ & $-0.31 * * *$ & $-0.32 * * *$ & $-0.50 * * *$ & $-0.18^{*}$ \\
\hline General & $-0.49 * * *$ & $-0.47 * * *$ & $-0.37 * * *$ & $-0.35^{* * *}$ & $-0.43 * * *$ & $-0.30 * * *$ \\
\hline Sum of Q-LES-Q & $-0.56 * * *$ & $-0.49 * * *$ & $-0.45 * * *$ & $-0.4 I * * *$ & $-0.52 * * *$ & $-0.35^{* * *}$ \\
\hline
\end{tabular}

Notes: Statistically significant correlations (bold values): $* P<0.05$. $* * P<0.01$. $* * * P<0.001$.

Abbreviations: ISMI, Internalized Stigma of Mental Illness Scale; Q-LES-Q, Quality of Life Satisfaction and Enjoyment Questionnaire.

from others and to have suffered more attacks of the disorder. The finding is in agreement with the results of previous studies for both schizophrenia and depression. ${ }^{40,41}$

Most research focused on the topic of self-stigma shows a significant association between internalized stigma and the intensity of symptoms of depression, anxiety, and overall greater severity of psychopathology for various disorders. This has been addressed both internationally ${ }^{36}$ and nationally in the Czech Republic. ${ }^{20,29,42-44}$

The goal of this study was to discover whether self-stigma is an important predictor of the QoL as expressed by the sum of Q-LES-Q; otherwise, it would be stepwise eliminated from the regression analysis, where only the significant regression parameters were to be considered in the end. This backward stepwise regression analysis weighted by age gradually led to only four factors significantly predicting the QoL: the employment status, subjectively evaluated severity of the disorder (subjCGI-S), the difference between the objective and subjective severity of the disorder (objCGI-subCGI-S), and the overall measure of self-stigma as expressed by the overall score of ISMI.

Thus, the current mental status of the patients as evaluated by themselves seems to have an impact on the patient's perception of their current situation and their ability to function in various areas of life. The finding corresponds with the study of Górna et a ${ }^{45}$ in schizophrenic patients, where the objective severity of the disorder also correlated with the QoL. Similarly, the study of Shargh et a ${ }^{46}$ revealed that patients who feel more severely mentally ill have a low QoL, and the extensive study of Priebe et a ${ }^{47}$ demonstrated that the symptom changes (particularly in depression/anxiety) influence the QoL.

\section{Limitations of the present study}

Most of the data were obtained using self-reported questionnaires, which can be considered limiting regarding subjective bias; this is true except for demographic information and the objectively evaluated objCGI severity score. Had the group sample size been larger, significant results could have been identified even when they were currently missed. The precise type and dosage of the medication were not monitored in this study. It is a limitation of the survey. Another limitation is that we did not use any instrument for the measurements of the level of depression in this study. Therefore, it is not possible to compare depressive scores of both groups. That is why it is difficult to show that the effect is real between the two groups (schizophrenia spectrum disorder and depressive disorder participants). Another limitation was that the interrater reliability of the psychiatrist was not made. Finally

Table 7 Multiple regression analysis with the sum of Q-LES-Q as a dependent variable weighted by age, and controlled for collinearity

\begin{tabular}{lllllll}
\hline Model & Regressors & B & SE & $\beta$ & t & Significance \\
\hline 9 & Employment & -31.179 & 7.794 & -0.247 & -4.001 & 0.000 \\
& objCGI-subjCGI-severity score & -8.986 & 3.646 & -0.176 & -2.465 & 0.015 \\
& Number of hospitalizations & 1.765 & 1.034 & 0.107 & 1.707 & 0.090 \\
& subjCGI-S & -21.938 & 3.779 & -0.442 & -5.806 & 0.000 \\
& ISMI overall score & -1.695 & 0.302 & -0.377 & -5.618 & 0.000 \\
& ANOVA: $F=36.138, d f=\mid 44 ; P<0.00 I$; adjusted $r^{2}=0.550$ & & & & \\
\hline
\end{tabular}

Abbreviations: ANOVA, analysis of variance; ISMI, Internalized Stigma of Mental Illness Scale; objCGI, objective Clinical Global Impression; Q-LES-Q, Quality of Life Satisfaction and Enjoyment Questionnaire; SE, standard error; subjCGI, subjective Clinical Global Impression; B, unstandardized regression coefficient; $\beta$, standardized regression coefficient; $t, t$ statistic. 
and most importantly, longitudinal observation would be preferable to a cross-sectional study, as it is more reliable and the changes in QoL and self-stigma during the different phases of the treatment could be helpful for the identification of causality. Notwithstanding these limitations, we still believe that this study represents a meaningful comparison of the QoL and self-stigma in the outpatient population with depressive and schizophrenia spectrum disorders.

\section{Conclusion}

This study demonstrates that the degree of the internalized stigma is a major factor that can be linked to the QoL in both diagnostic categories explored. The overall QoL did not differ much between the two groups, while the tendency to self-stigmatize was significantly higher for the patients with schizophrenia spectrum disorders than for the patients with depressive disorders. It seems that the actual severity of the mental disorder at the given time plays a major role in both the QoL and the levels of self-stigma. Longitudinal research that would monitor the development of these variables over a longer period might be the next step to imply the causalities involved.

\section{Acknowledgments}

The authors express their deep gratitude to Dr Jiří Rozkoš from Prostějov, Dr Jan Flídr from Kralupy nad Vltavou, Dr Jana Matějková from Prague, Dr Simona Papežové from Prague, Dr Pavel Tautermann from Prague, Dr Markéta Zemanová from Havlíčkův Brod, Dr Markéta Dobrá from Hrabyně, Dr Zuzana Kozáková from Trutnov (RIAPS Association), Dr Tibor Miklóš from Prague, Dr Michaela Zapletalová from Chomutov, Dr Jana Novosadová from Blansko, Dr Jiř́ Trska from Týn nad Vltavou, Dr Zdeněk Holoubek from Nymburk, Dr Iva Ondráčková from Prague, Dr Andrea Bryčková from Hořice, Dr Jindřiška Masnerová from Beroun, Dr Petr Pastucha from Prostějov, and Dr Hana Lemanová from Brno for their kind and willing cooperation.

\section{Disclosure}

The authors report no conflicts of interest in this work.

\section{References}

1. Giammanco MD, Gitto L. Coping, uncertainty and health-related quality of life as determinant of anxiety and depression on a sample of hospitalized cardiac patients in southern Italy. Psychol Health Med. 2016;25(11):2941-2956.

2. Svoboda M, Češková E, Kučerová H. Psychopatologie a psychiatrie [The Psychopathology and Psychiatry]. Praha: Portál; 2006.

3. Latalova K, Prasko J, Kamaradova D, et al. Self-stigma and suicidality in patients with neurotic spectrum disorder - a cross sectional study. Neuro Endocrinol Lett. 2014;35(6):474-480.
4. Rusch N, Zlati A, Black G, Thornicroft G. Does the stigma of mental illness contribute to suicidality. British J Psychiatr. 2014; 205(4):257-259.

5. Scocco P, Toffol E, Antonio P, SOPRoxi Project Team. Psychological distress increases perceived stigma toward attempted suicide among those with a history of past attempted suicide. J Nerv Ment Dis. 2016; 204(3):194-202.

6. Bengtsson-Tops A, Hansson L. Clinical and social needs of schizophrenic outpatients living in the community: the relationship between needs and subjective quality of life. Soc Psychiatry Psychiatr Epidemiol. 1999;34(10):513-518.

7. Hansson L, Sandlund M, Bengtsson-Tops A, et al. The relationship of needs and quality of life in persons with schizophrenia living in the community. A Nordic multicenter study. Nord J Psychiatry. 2003; 57(1):5-11.

8. Papakostas G, Petersen T, Mahal Y, Mischoulon D, Nierenberg AA, Fava M. Quality of life assessments in major depressive disorder: a review of the literature. Gen Hosp Psychiatry. 2004;26(1):13-17.

9. Sidlova M, Prasko J, Jelenova D, et al. The quality of life of patients suffering from schizophrenia - a comparison with healthy controls. Biomed Pap Med Fac Univ Palacky Olomouc Czech Rep. 2011; 155(2):173-180

10. Holubova M, Prasko J, Latalova K, et al. Are self-stigma, quality of life, and clinical data interrelated in schizophrenia spectrum patients? A cross-sectional outpatient study. Patient Prefer Adherence. 2016; 10:265-274.

11. Bowling A. The concept of quality of life in relation to health. Medicina Nei Secoli Arte E Scienza. 1995;7:633-645.

12. Latalova K, Prasko J, Diveky T, Kamaradova D, Velartova H. Quality of life in patients with bipolar disorder - a comparison with schizophrenic patients and healthy controls. Psychiatr Danub. 2011;23(1):21-26.

13. Holubova M, Prasko J, Hruby R, et al. Coping strategies and self-stigma in patients with schizophrenia-spectrum disorders. Patient Prefer Adherence. 2016;10:1151-1158.

14. Latalova K, Kamaradova D, Prasko J. Perspectives on perceived stigma and self-stigma in adult male patients with depression. Neuropsychiatr Dis Treat. 2014;10:1399-1405.

15. Ocisková M, Praško J, Kamarádová D, et al. Self-stigma in psychiatric patients - standardization of the ISMI scale. Neuro Endocrinol Lett. 2014;35(7):624-632.

16. Livingston JD, Boyd JE. Correlates and consequences of internalized stigma for people living with mental illness: a systematic review and meta-analysis. Soc Sci Med. 2010;71(12):2150-2161.

17. Corrigan PW, Rafacz J, Rüsch N. Examining a progressive model of self-stigma and its impact on people with serious mental illness. Psychiatry Res. 2011;189(3):339-343.

18. Tucker JR, Hammer JH, Vogel DL, Bitman RL, Wade NG, Maier EJ. Disentangling self-stigma: are mental illness and help-seeking selfstigmas different? J Couns Psychol. 2013;60(4):520-531.

19. Ociskova M, Prasko J, Kamaradova D, Grambal A, Sigmundova Z. Individual correlates of self-stigma in patients with anxiety disorders with and without comorbidities. Neuropsychiatr Dis Treat. 2015;11: $1767-1779$

20. Vrbová K, Kamarádová D, Látalová K, et al. Self-stigma and adherence to medication in patients with psychotic disorders - a cross-sectional study. Neuro Endocrinol Lett. 2014;35(7):645-652.

21. Gerlinger G, Hauser M, De Hert M, Lacluyse K, Wampers M, Correll CU. Personal stigma in schizophrenia spectrum disorders: a systematic review of prevalence rates, correlates, impact, and interventions. World Psychiatry. 2013;12(2):155-164.

22. Kamaradova D, Latalova K, Prasko J, et al. Sebestigmatizace, adherence k léčbě a vysazování medikace u psychických poruch - průřezová studie [Self-stigma, adherence to treatment and withdrawal of medication in psychiatric disorders - a cross-sectional study]. Psychiatrie. 2015; 19(4):175-183.

23. Sedlackova Z, Kamaradova D, Prasko J, et al. Treatment adherence and self-stigma in patients with depressive disorder in remission - a crosssectional study. Neuro Endocrinol Lett. 2015;36(2):171-177. 
24. Schulze B, Angermeyer MC. Subjective experiences of stigma: a focus group study of schizophrenic patients, their relatives, and mental health professionals. Soc Sci Med. 2003;56(2):299-312.

25. Ritsher JB, Phelan JC. Internalized stigma predicts the erosion of morale among psychiatric outpatients. Psychiatry Res. 2004;129(3): 257-265.

26. Tsang HW, Fung KM, Chung RC. Self-stigma and stages of change as predictors of treatment adherence of individuals with schizophrenia. Psychiatry Res. 2010;180(1):10-15.

27. Ociskova M, Prasko J, Vrbova K, Kamaradova D, Jelenova D, Latalova K. Stigma and self-stigma in patients with schizophrenia. Česká Slov Psychiatr. 2014;110(5):250-258.

28. Uhlmann C, Kaehler J, Harris MS, Unser J, Arolt V, Lencer R. Negative impact of self-stigmatization on attitude toward medication adherence in patients with psychosis. J Psychiatr Pract. 2014;20(5):405-410.

29. Kamaradova D, Latalova K, Prasko J, et al. Connection between selfstigma, adherence to treatment, and discontinuation of medication. Patient Prefer Adherence. 2016;10:1289-1298.

30. Tang IC, Wu HC. Quality of life and self-stigma in individuals with schizophrenia. Psychiatr Q. 2012;83(4):497-507.

31. Ociskova M, Prasko J, Kamaradova D, Grambal A, Latalova K, Sigmundova Z. Relationship between internalized stigma and treatment efficacy in mixed neurotic spectrum and depressive disorders. Neuro Endocrinol Lett. 2014;35(8):711-717.

32. World Health Organization. The ICD-10 Classification of Mental and Behavioral Disorders: Diagnostic Criteria for Research. Geneva: World Health Organization; 1993.

33. Ritsner M, Kurs R, Ratner Y, Gibel A. Condensed version of the Quality of Life Scale for schizophrenia for use in outcome studies. Psychiatry Res. 2005;135(1):65-75.

34. Müllerova H. Mezikulturní přenos a validace dotazníku kvality života Q-LES-Q [Transcultural transmission and validation of the life quality questionnaire Q-LES-Q]. Psychiatrie. 2001;5:80-87.

35. Ritsher JB, Otilingam PG, Grajales M. Internalized stigma of mental illness: psychometric properties of a new measure. Psychiatry Res. 2003;121(1):31-49.

36. Boyd JE, Adler EP, Otilingam PG, Peters T. Internalized Stigma of Mental Illness (ISMI) scale: a multinational review. Compr Psychiatry. 2014;55(1):221-231.
37. Guy W, editor. ECDEU Assessment Manual for Psychopharmacology. Rockville: US DHEW; 1976.

38. Zaider TI, Heimberg RG, Fresco DM, Schneier FR, Liebowitz MR. Evaluation of the clinical global impression scale among individuals with social anxiety disorder. Psychol Med. 2003;33:611-622.

39. European Medicines Agency. Guideline for Good Clinical Practice ICH. Harmonized Tripartite Guideline. 2003:59. Available from: http:// www.edctp.org/fileadmin/documents/EMEA_ICH-GCP_Guidelines_ July_2002.pdf. Accessed October 28, 2016

40. Vrbova K. Sebestigmatizace u pacientů s poruchami schizofrenního spektra. In Czech [Self-stigma in patients with schizophrenia spectrum disorders]. Česká Slov Psychiatr. In press 2016.

41. Prasko J, Ociskova M, Grambal A, et al. Personality features, dissociation, self-stigma, hope, and the complex treatment of depressive disorder. Neuropsychiatr Dis Treat. 2016;12:2539-2552.

42. Hajda M, Kamaradova D, Latalova K, et al. Self-stigma, treatment adherence, and medication discontinuation in patients with bipolar disorders in remission - a cross sectional study. Act Nerv Super Rediviva. 2015;5(1-2):6-11.

43. Ociskova M, Prasko J, Latalova K, Kamaradova D, Grambal A. Psychological factors and treatment effectiveness in resistant anxiety disorders in highly comorbid inpatients. Neuropsychiatr Dis Treat. 2016;12:1539-1551.

44. Ocisková M, Praško J, Látalová $\mathrm{K}$, et al. Internalizované stigma a efektivita farmakoterapie a psychoterapie u úzkostných poruch a poruch neurotického spektra [Internalized stigma and efficacy of pharmacotherapy and psychotherapy in anxiety disorders and neurotic spectrum disorders]. Česká Slov Psychiatr. 2014;110(3):133-143.

45. Górna K, Jaracz K, Wrzyszczyńska L, Rybakowski F. Quality of life and depression in schizophrenic patients. Adv Med Sci. 2007;52(suppl 1): 108-111.

46. Shargh AB, Rostami B, Kosari B, Zakiye T, Majelan GA. Study of relationship between depression and quality of life in patients with chronic schizophrenia. Global J Health Sci. 2015;8(3):224-229.

47. Priebe S, McCabe R, Junghan U, et al. Association between symptoms and quality of life in patients with schizophrenia: a pooled analysis of changes over time. Schizophr Res. 2011;133(1-3):17-21.
Neuropsychiatric Disease and Treatment

\section{Publish your work in this journal}

Neuropsychiatric Disease and Treatment is an international, peerreviewed journal of clinical therapeutics and pharmacology focusing on concise rapid reporting of clinical or pre-clinical studies on a range of neuropsychiatric and neurological disorders. This journal is indexed on PubMed Central, the 'PsycINFO' database and CAS,

\section{Dovepress}

and is the official journal of The International Neuropsychiatric Association (INA). The manuscript management system is completely online and includes a very quick and fair peer-review system, which is all easy to use. Visit http://www.dovepress.com/testimonials.php to read real quotes from published authors. 